István FODOR

Ferenc KRANJEC

László ÓZSVÁRI

\title{
1.6. NEW METHODS IN THE EVALUATION OF REPRODUCTIVE PERFORMANCE IN THE HUNGARIAN DAIRY HERDS
}

\begin{abstract}
Summary
The aim of this study is to assess the average values of the most commonly used reproductive indices, to introduce more recent parameters for measuring reproductive performance and to suggest reference values for the latter, based on a survey carried out in Hungary. Data were collected from February to May 2015, and altogether 12,723 cows were included from 21 herds in six counties. Average values of the conventional indices were: SP: 160 days, SPC: 4.27 and CR1: 22\%. The SP, SPC and CR1 were much poorer than the former reference values even in the best herds. It was proven that $\mathrm{PR}$ is suitable for a quick review of the reproductive performance; therefore this parameter is advised for routine use in dairies. In this study, cPR was introduced as a novel parameter that is destined for overcoming inaccuracies stemming from Hungarian culling policy. Suggested reference values of the more recent parameters are: PR: $9.4 \%$, cPR: 18\%. \%PORP is preferable to \%Preg, since it applies only to the reproductive proportion of the herd, and its value is not influenced by the seasonal changes (calving, culling) to such a great extent and for such a long time. The use of some relevant parameters (PR, cPR, CR1, SP, \%PORP) is enough for the daily routine, but in-depth analysis is required when the reproductive performance is diminishing.
\end{abstract}

Keywords: reproduction, dairy cattle, evaluation, parameter, pregnancy rate

\author{
Abbreviations \\ \%CULL: Percentage of culled cows \\ \%PORP: Percentage pregnant in ORP \\ $\%$ Preg: Percentage pregnant \\ \%Preg200: Percentage pregnant within \\ 200 DIM \\ bST: bovine somatotropin \\ cPR: Corrected Pregnancy Rate \\ CR: Conception Rate \\ CR1: Conception rate of first inseminations \\ DIM: Days in Milk \\ DS1I: Days to successful first insemination \\ HDR: Heat Detection Rate \\ IBI: Interbreeding interval
}

O285: Open cows beyond 285 DIM

O60: Open cows beyond 60 DIM

ORP: optimal reproductive population

PR: Pregnancy Rate

PRP200: Pregnancy rate of pregnant

cows within 200 DIM

R21: Re-insemination at 12-21 days

SP: Service period

SP200: Service period within 200 DIM

SPC: Services per conception

SPCP200: Services per conception

of pregnant cows within 200 DIM

VWP: Voluntary Waiting Period 
Fodor, I. - Kranjec, F. - Ózsvári, L.

\section{Introduction}

The primary source of income of the dairy farms is the amount of milk sold. Profitability is fundamentally influenced by the reproductive success of the herd. Reproductive disorders lead to longer calving interval (therefore, both the annual milk production and the number of calves born are decreased), more involuntary cullings, excess semen usage and higher veterinary costs. The economic consequences of these effects can be quantified (Ózsvári, 2013; Ózsvári - Kerényi, 2004).

Milk production of the Holstein-Friesian cows has increased dramatically in the recent decades, which - together with other factors, such as environmental issues (e. g. climate change), more intensive nutrition, housing, genetic changes - altered the reproductive characteristics of this breed, as well (Lucy, 2001). The length of oestrus has decreased from 12-15 hours to approximately 8 hours on average, moreover, the signs of oestrus have become less pronounced, as well (Nebel, 1993; Nebel et al., 2000). The length of the oestrus cycle has increased from 20.3 days to 22.3 days, fertility of the first inseminations has decreased by $15.9 \%$ and calving interval has become 20 days longer in the period involved in a study (Stevenson, 2011).

The built-in analyses of the widely used farm management software and evaluation systems usually put large emphasis on some more conventional reproductive indices in Hungary, such as productivity, calving interval, services per conception and the proportion of pregnant cows. The way of calculating productivity is inconsistent in the different books and softwares, furthermore, this index is usually considered outdated (Pécsi, 2007). Calving interval should be used prudently, as well, since this parameter does not take primiparous cows into account, which may account for $30-40 \%$ of a dairy herd. Furthermore, this parameter can be considered historical, because events which occurred up to 2 years before the date of the evaluation are involved (Farin $\&$ Slenning, 2001; Fetrow et al., 2007).

Increased number of services per conception account for $6.5-13.4 \%$ of reproductive losses, which can cause a five-digit loss in euro in large scale dairy herds, however, even the minor increase of the service period leads to larger economic losses (Fodor, 2011; Ózsvári, 2004; Ózsvári, 2013). This parameter has been generally used for the evaluation of the inseminators' work, however, the reproductive success is influenced by a number of factors, which can be quantified by more relevant parameters. Culled cows and cows that have recently calved and are therefore not suitable for insemination are often involved in the calculation of the proportion of pregnant cows, which causes interferences at the evaluation. Outdated reference values are often used at the evaluation of the conventional indices, which are not realistic goals in the modern, high-yielding, intensively managed herds, where the reproductive performance of the cows is impaired.

Different housing and milking technologies, farm management softwares and protocols have been imported from the US to Hungary in the recent years. These farmers usually use the imported parameters and reference values in the reproductive management. However, there are a number of fundamental differences between the reproductive management in the US and in Hungary. In the US, the VWP (Voluntary Waiting 
Period) is widely used in the dairies. VWP indicates the period after calving until the cows remain deliberately unserved, which usually lasts for 60 days. Culling criteria are essentially different, as well: cows are usually not inseminated beyond 200 DIM and below $30 \mathrm{~kg}$ daily milk yield (DCRC, 2014). The usage of bST and timed insemination programmes are common in US dairies, semen and drug costs are significantly lower, labor cost is significantly higher and the quality of feedstuff is more balanced, all of which underpin the idea that the reference values used in the US cannot be used directly among the Hungarian circumstances. HDR, CR and PR are routinely analysed when evaluating reproductive performance. A simple mathematical equation describes the relationship among these parameters: $\mathrm{HDR}^{*} \mathrm{CR}=\mathrm{PR}$. Heat Detection Rate shows the proportion of cows actually inseminated within a 21-day period (which equals to the length of the oestrous cycle) that of eligible for insemination within the same time frame. Conception Rate is actually the inverse of the services per conception.

Pregnancy Rate indicates the number of conceived animals that of eligible for insemination within a 21-day period. The major advantage of PR is that it covers the efficiency of the reproductive management, the fertility of the herd and the time, as well. The farm management softwares commonly used in Hungarian dairy farms are not capable of calculating PR or do not calculate PR properly, since these are unable to collect data according to the 21-day long oestrus cycle. The underlying principle behind the calculation of PR is that the number of pregnant cows has to be divided by the number of possible oestrus cycles in the optimal reproductive population (ORP), irrespective of being inseminated or not. ORP consists of the the cows beyond the VWP that have not yet been culled.

According to these factors, the evaluation of reproductive performance varies greatly among dairy farms in Hungary. Firstly, the authors aimed to determine new, achievable reference numbers for the conventional parameters. Secondly, more relevant reproductive indices were defined and their reference numbers were suggested in this work. Thirdly, corrected PR (cPR), as a new parameter for measuring reproductive success, was developed and its suitability for routine use was tested. Corrected PR was developed to tailor PR to the Hungarian circumstances, thus, its advantages can be pushed.

\section{Materials and methods}

The authors surveyed production and reproduction indices and the reproductive management in large-scale Hungarian dairy herds. The data of 12,723 cows were collected in 21 herds in six Hungarian counties between February and May 2015.

Herd-level reproductive data - regarding the performance of 2014 - originated from the built-in analyses of the farm management software RISKA, which was used in all of the surveyed dairy herds. Cow-level data were also collected from RISKA (ear tag number, date of calving, parity, status code $[0=$ open, not inseminated; $1=$ inseminated; 2 = pregnant], date of last insemination, number of last insemination, last test-day milk yield, date of culling), which were used in the calculation of different reproductive parameters. 
Fodor, I. - Kranjec, F. - Ózsvári, L.

Reproductive indices were grouped according to the proportion of the herd included in the calculation of the respective parameter. Parameters were grouped according to their availability from the farm management software, as well, since several indices were not readily available in RISKA, and were calculated from the cow-level data. However, the optimal VWP varies among dairies to a limited extent, 60 days was uniformly used in this work.

\section{Parameters considering all cows}

These parameters are readily available in the farm management software used in the present study. All cows in the herd are included in the calculation of these indices. The performance of the herds in 2014 was examined.

- Percentage of culled cows (\%CULL): indicates the percentage of cull candidates and already culled cows.

- Open cows beyond 60 DIM (O60): indicates the percentage of not inseminated, or inseminated, but open and not re-inseminated cows. The denominator is the number of non-cull cows beyond the VWP.

- Service period (SP): indicates the average time it takes for the cows to conceive. Only pregnant cows are considered. $\mathrm{SP}=\Sigma$ DIM to conception (pregnant cows) / number of pregnant cows.

- Interbreeding interval (IBI): indicates the average number of days between two subsequent inseminations.

- Re-insemination at 12-21 days (R21): indicates the percentage of reinseminations carried out 12-21 days after the previous insemination within the total number of re-inseminations.

- Services per conception (SPC): indicates the total number of inseminations carried out in a period divided by the number of conceived cows in the same period.

- Days to successful first insemination (DS1I): the average service period of the cows that conceived for the first insemination.

- Conception rate of first inseminations (CR1): indicates the percentage of cows in a period that conceived for the first insemination.

- Percentage pregnant (\%Preg): indicates the proportion of pregnant cows as a percentage of the total number of cows in the herd.

\section{Parameters considering ORP cows}

Cows beyond VWP and not culled were regarded as ORP cows. Only these cows were taken into account at the calculation of the following indices. Since open cows beyond 200 DIM are usually culled in the US, it was used as a reference here, as well. On the one hand, these indices describe reproductive performance in a more realistic way, on 
the other hand, they facilitate the comparison of the results of the dairies internationally.

- Percentage pregnant in ORP (\%PORP): cull cows are not taken into account, because they should not be inseminated. Similarly, if VWP is strictly applied (here 60 days), then pregnant cows should only be searched for among the cows that calved before this date.

- Service period within 200 DIM (SP200): SP was quantified for every single pregnant cow, and the average SP was calculated for those conceiving within 200 DIM.

- Percentage pregnant within 200 DIM (\%Preg200): expresses the percentage of pregnant cows with an SP below 200 days.

- Services per conception of pregnant cows within 200 DIM (SPCP200): expresses the average number of inseminations needed for those cows conceiving within 200 DIM.

- Open cows beyond 285 DIM (O285): indicates the percentage of cows within the ORP, which have been milking for more than 285 days, produce less than $25 \mathrm{~kg}$ milk daily and are open.

- Pregnancy Rate (PR): the theoretically possible number of oestrus cycles of the pregnant cows was calculated by subtracting VWP from the SP, and this was divided by 21 . The result was rounded upwards (e.g. if the quotient was 1.24, then it should be rounded up to 2). The way of calculation is similar in the case of the nonpregnant cows, as well, but VWP was subtracted from DIM. The possible number of oestrus cycles was summed up for all the ORP cows and the number of pregnant cows was divided by the sum.

- Corrected Pregnancy Rate (cPR): for those cows conceiving within 200 DIM, the number of pregnant cows was divided by the total number of possible oestrus cycles until conception, as described at PR. Actually, this way the pregnancy rate of pregnant cows within 200 DIM was calculated (PRP200). Assuming that during the same period (i.e. average number of days to conception of the pregnant cows) equal number of oestrus cycles occurred in the nonpregnant population, as well, cPR was calculated as follows: cPR $=$ PRP200 / 2 .

Production and reproduction parameters were analysed by Microsoft Excel ${ }^{\circledR}$.

\section{Results and discussion}

\section{Evaluation of the reproductive performance of the surveyed herds}

The most important production and reproduction parameters of the surveyed herds are shown in Table 1. 
Fodor, I. - Kranjec, F. - Ózsvári, L.

Table 1: Production and reproduction parameters of the herds

\begin{tabular}{|l|c|c|c|}
\hline \multicolumn{1}{|c|}{ Parameter } & Average & Minimum & Maximum \\
\hline Number of cows & 606 & 169 & 1269 \\
\hline \%CULL & 5 & 0 & 17 \\
\hline Lactational milk yield (kg) & 9851 & 8200 & 12174 \\
\hline O60 (\%) & 12 & 2.2 & 34 \\
\hline SP (days) & 160 & 125 & 205 \\
\hline IBI (days) & 29 & 23 & 38 \\
\hline R21 (\%) & 46 & 26 & 61 \\
\hline SPC & 4.27 & 2.8 & 7.2 \\
\hline DS1I (days) & 76 & 52 & 107 \\
\hline CR1 (\%) & 22 & 14 & 36 \\
\hline \%Preg & 43 & 28.8 & 60.5 \\
\hline \%PORP & 53 & 37 & 67 \\
\hline SP200 (days) & 109 & 95 & 121 \\
\hline \%Preg200 & 72 & 56 & 86 \\
\hline SPCP200 & 2.06 & 1.49 & 2.41 \\
\hline PR (\%) & 10 & 4.4 & 16 \\
\hline cPR (\%) & 18 & 14.6 & 23.11 \\
\hline
\end{tabular}

Source: own calculation

Remarkable differences can be found among the dairy herds. Table 1 . shows that the performance of the dairies do not comply with the former - but commonly used reference values. Suggested values for SP was below 115 days, $>60 \%$ for CR1 and 1.5-2.2 for SPC (Radostits et al., 1994; Szenci, 1999). It is remarkable, that even the best herds could not reach these goals set up in the ' 90 s.

The herds were ordered according to their PR, and by ignoring the results of the four best and four worst dairies, "tightened" averages of the examined parameters were calculated. A difference exceeding two percentage points was found only in the case of R21 (average: 45.7\%, "tightened average": 42.2\%), which underpins that the "Average" numbers shown in Table 1. can be reached even among average Hungarian circumstances, but herds with such or worse results should improve reproduction.

In order to evaluate PR compared to the other parameters, the reproductive indices of the four best and the four worst dairies (ordered by PR) were summarized (Table 2). 
1.6. New methods in the evaluation of reproductive performance in the Hungarian dairy herds

Table 2: Reproduction parameters of the herds with the four best and four worst Pregnancy Rate

\begin{tabular}{|c|c|c|c|c|c|c|c|c|c|c|c|}
\hline \multirow[t]{2}{*}{ Parameter } & \multicolumn{4}{|c|}{$\begin{array}{c}\text { Herds with the best } \\
\text { PR }\end{array}$} & \multicolumn{4}{|c|}{$\begin{array}{l}\text { Herds with the worst } \\
\text { PR }\end{array}$} & \multicolumn{2}{|c|}{ Average } & \multirow[t]{2}{*}{\begin{tabular}{|c} 
Differ- \\
ence
\end{tabular}} \\
\hline & $\mathbf{A}$ & B & \begin{tabular}{|l|}
$\mathbf{C}$ \\
\end{tabular} & D & $\mathbf{E}$ & $\mathbf{F}$ & G & $\mathbf{H}$ & „Good" & „Bad” & \\
\hline $\begin{array}{l}\text { Number of } \\
\text { cows }\end{array}$ & 1012 & 723 & 412 & 1081 & 487 & 279 & 480 & 402 & 807 & 412 & \\
\hline $\begin{array}{l}\text { Lactational } \\
\text { milk yield } \\
\text { (kg) }\end{array}$ & 9200 & 10800 & 9300 & 9500 & 9900 & 9600 & 9400 & 8900 & 9700 & 9450 & \\
\hline SP (days) & 131 & 125 & 134 & 131 & 163 & 166 & 205 & 168 & 130.3 & 175.5 & $+35 \%$ \\
\hline R21 (\%) & 60 & 49 & 50 & 52 & 47 & 28 & 56 & 26 & 52.8 & 39.3 & $-26 \%$ \\
\hline CR1 (\%) & 25 & 36 & 27 & 27 & 19 & 17 & 21 & 21 & 28.8 & 19.5 & $-32 \%$ \\
\hline$\%$ PORP & 67 & 59 & 60 & 55 & 41 & 42 & 44 & 59 & 60.3 & 46.5 & $-23 \%$ \\
\hline$\%$ Preg & 61 & 47 & 50 & 47 & 34 & 35 & 34 & 48 & 50.9 & 37.8 & $-26 \%$ \\
\hline $\begin{array}{l}\text { SP200 } \\
\text { (days) }\end{array}$ & 103 & 101 & 101 & 102 & 121 & 110 & 121 & 114 & 101.8 & 116.5 & $+14 \%$ \\
\hline$\%$ Preg200 & 83 & 86 & 82 & 82 & 74 & 72 & 56 & 71 & 83.3 & 68.3 & $-18 \%$ \\
\hline PR (\%) & 16 & 15.8 & 13.1 & 12.3 & 7.1 & 6.9 & 5.9 & 4.4 & 14.3 & 6.1 & $-58 \%$ \\
\hline cPR (\%) & 19.6 & 20.5 & 20.3 & 20.0 & 14.7 & 17.7 & 14.6 & 16.3 & 20.1 & 15.8 & $-21 \%$ \\
\hline $\mathrm{O} 285(\%)$ & 1.2 & 0.0 & 1.3 & 2.4 & 6.2 & 2.6 & 7.8 & 3.5 & 1.2 & 5.0 & $+316 \%$ \\
\hline SPC & 3.78 & 3.2 & 3.2 & 3.3 & 6.2 & 5.1 & 4.1 & 4.2 & 3.4 & 4.9 & $+44 \%$ \\
\hline
\end{tabular}

Source: own calculation

Herd size is remarkably different between the two groups, while lactational milk yield is similar. Herds with better PR outperformed the other group regarding all the parameters. The difference exceeded $20 \%$ in several parameters (SP: 35\%, R21: 26\%, CR1: 32\%, \%PORP: 23\%, \%Preg: 26\%, cPR: 21\%). Results of these herds support that good reproductive performance can be achieved on Holstein-Friesian farms despite larger herd size and high milk yield. Huge difference was found regarding O285 (316\%) and SPC (44\%), which called for further analysis.

The dairies were ranked by all of the reproductive indices in order to examine the relationship between PR and culling intensity, the latter being expressed by $\mathrm{O} 285$. After that, farms were ordered according to their PR and their ranks in other indices were analysed (Table 3). 
Fodor, I. - Kranjec, F. - Ózsvári, L.

Table 3: Ranks of the surveyed dairy herds in the different reproductive indices

\begin{tabular}{|c|c|c|c|c|c|c|c|c|c|c|}
\hline & \multirow[b]{2}{*}{$\mathbf{O 2 8 5}$} & \multicolumn{8}{|c|}{ Rank in the respective parameter } & \multirow[b]{2}{*}{ Average } \\
\hline & & $\mathbf{P R}$ & cPR & $\begin{array}{c}\mathrm{O} 28 \\
5\end{array}$ & SP & $\begin{array}{c}\text { CR } \\
1\end{array}$ & $\%$ PORP & SP200 & $\%$ Preg200 & \\
\hline \multirow{10}{*}{$\begin{array}{l}\text { PR\% 1- } \\
10 .\end{array}$} & $1.2 \%$ & 1 & 6 & 2 & 2 & 8 & 1 & 5 & 2 & 3 \\
\hline & $0.0 \%$ & 2 & 2 & 1 & 1 & 1 & 5 & 3 & 1 & 2 \\
\hline & $1.3 \%$ & 3 & 3 & 4 & 4 & 4 & 4 & 2 & 3 & 3 \\
\hline & $2.4 \%$ & 4 & 4 & 9 & 3 & 5 & 9 & 4 & 4 & 5 \\
\hline & $1.6 \%$ & 5 & 12 & 5 & 6 & 7 & 2 & 10 & 5 & 7 \\
\hline & $2.1 \%$ & 7 & 8 & 8 & 11 & 16 & 3 & 8 & 15 & 10 \\
\hline & $2.8 \%$ & 6 & 9 & 12 & 14 & 14 & 7 & 9 & 11 & 10 \\
\hline & $3.1 \%$ & 8 & 1 & 13 & 5 & 6 & 10 & 1 & 7 & 6 \\
\hline & $2.0 \%$ & 9 & 13 & 7 & 8 & 12 & 16 & 13 & 13 & 11 \\
\hline & $3.1 \%$ & 10 & 5 & 14 & 16 & 17 & 8 & 6 & 16 & 12 \\
\hline Average & $2.0 \%$ & 6 & 6 & 8 & 7 & 9 & 7 & 6 & 8 & 7 \\
\hline \begin{tabular}{|l|} 
PR\% \\
$11-21$. \\
Average
\end{tabular} & $3.7 \%$ & 15 & 14 & 13 & 13 & 11 & 14 & 14 & 13 & 13 \\
\hline
\end{tabular}

Source: own calculation

The first 10 farms according to PR generally outperformed the others in $\mathrm{O} 285$ (average O285 rank 8 vs. 13), which means that the proportion of open cows beyond 285 DIM (i.e. in the lower-producing period of the lactation) was smaller in these herds. These herds outperformed the others regarding the other parameters, as well.

The herds were ranked according to SPC, and their results in SP, CR1, SP200 and PR were analysed (Table 4).

Table 4: Reproductive indices of the surveyed herds with best SPC

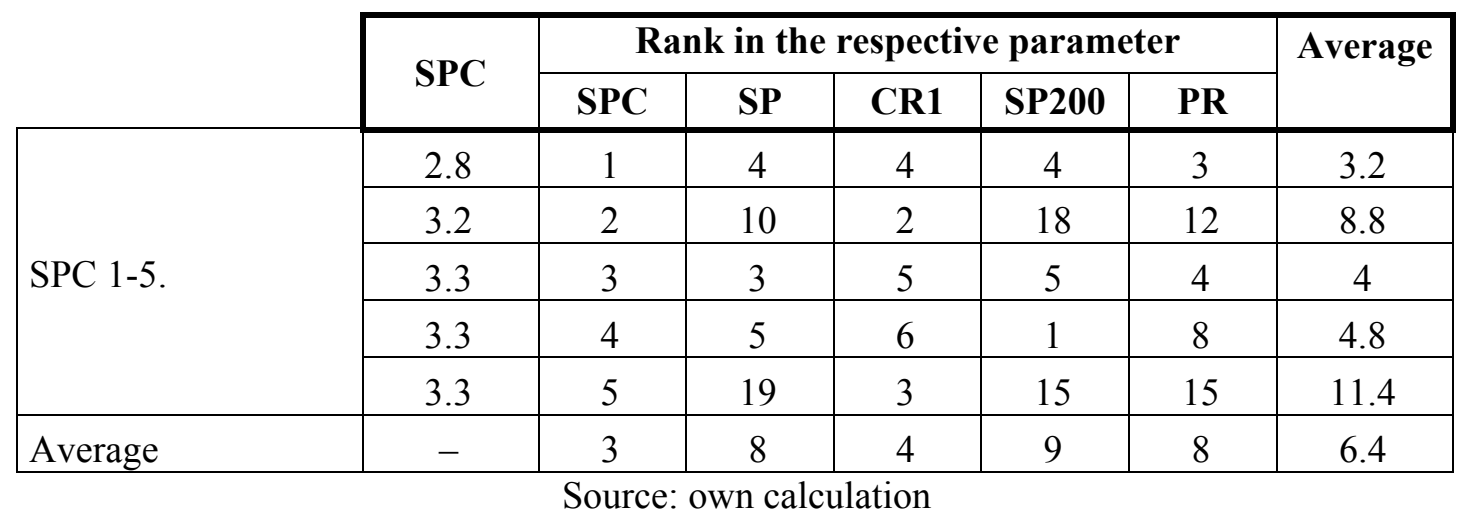


The best performing herds in terms of SPC achieved poor results in other parameters, especially in SP, SP200 and PR. E.g. the herd with second best SPC was only $10^{\text {th }}$ in SP, $18^{\text {th }}$ in SP200 and $12^{\text {th }}$ in PR. It can be explained by the common practice that the work of the inseminators is often evaluated based on the SPC, who, therefore, tend to inseminate only the cows which will most probably conceive. It leads to longer SP and lower PR.

\section{The applicability of cPR in the practice}

cPR, as a new index for measuring reproductive success, was developed to eliminate the effect of the culling habits of Hungarian farms - which are fundamentally different from that of the US - on PR. The relationship of cPR with PR and other parameters was analysed (Table 5).

The data of those herds were used in these analyses, where the difference between PR and cPR rank was remarkable, or the PR and cPR results of the herd were contradictory compared to the reference values (threshold: PR: 9.4, cPR: 18). This analysis was carried out because the primary aim of cPR is to highlight poor reproductive performance irrespective of culling intensity, even when PR is acceptable.

Table 5: The comparison of cPR with $P R$ and other reproductive parameters

\begin{tabular}{|c|c|c|c|c|c|c|}
\hline & \multirow{2}{*}{ Parameter } & \multicolumn{5}{|c|}{ Herd } \\
\hline & & $\mathbf{A}$ & B & $\mathbf{C}$ & D & $\mathbf{E}$ \\
\hline \multirow{6}{*}{ PR vs. cPR } & PR & 9.4 & 8.3 & 10.5 & 10.5 & 12.2 \\
\hline & $\mathrm{cPR}$ & 19.7 & 19.2 & 18.4 & 18.1 & 17.6 \\
\hline & PR rank & 10 & 13 & 7 & 6 & 5 \\
\hline & cPR rank & 5 & 7 & 8 & 9 & 12 \\
\hline & cPR rank - PR rank & -5 & -6 & 1 & 3 & 7 \\
\hline & $\mathrm{O} 285$ & 3.1 & 4.5 & 2.1 & 2.8 & 1.6 \\
\hline \multirow{5}{*}{$\begin{array}{l}\text { Rank in the } \\
\text { respective } \\
\text { parameter }\end{array}$} & SP & 16 & 7 & 11 & 14 & 6 \\
\hline & CR1 & 17 & 19 & 16 & 14 & 7 \\
\hline & $\%$ PORP & 8 & 15 & 3 & 7 & 2 \\
\hline & SP200 & 6 & 7 & 8 & 9 & 10 \\
\hline & $\%$ Preg200 & 16 & 10 & 15 & 11 & 5 \\
\hline
\end{tabular}

Source: own calculation 
Fodor, I. - Kranjec, F. - Ózsvári, L.

In herd $\mathrm{A}$ and $\mathrm{B}$ good cPR was achieved along with relatively high $\mathrm{O} 285$. On these farms SP200 was low (cows conceived quickly within 200 DIM), but the proportion of cows conceiving within 200 DIM (\%Preg200) was small. Therefore, PR and other reproductive indices turned out to be poor. In herds $\mathrm{C}, \mathrm{D}$ and $\mathrm{E}$ good $\mathrm{PR}$ was observed along with average $\mathrm{O} 285$; cPR was around the threshold. The latter group of farms had poor performance regarding other parameters, as well.

Based on the results, if PR is low and cPR is high, or PR is acceptable-good and cPR is around or below the threshold, culling and first inseminations should be supervised and other parameters should be examined, as well. The evaluation of cPR may complement the use of PR in the field, and it may be suitable for international comparisons, following more widespread field analysis.

\section{The applicability of PR and other suggested parameters in Hungarian dairies}

\section{Evaluation of $P R$ in the Hungarian dairy farms}

PR indicates both good and poor reproduction properly, therefore, the evaluation of this index is of paramount importance in the field work. In order to carry out more detailed evaluations of the reproductive performance, other parameters should be analysed, of course. However, PR is influenced greatly by culling intensity, low PR generally indicates poor reproduction.

In the herds experiencing high $\mathrm{O} 285$ and low $\mathrm{PR}$, reproductive management and culling should be supervised. Culling intensity is important from another point of view, as well: cows with lower fertility can influence the results of the whole herd, which may initiate incorrect management decisions. It is advised to complement PR with cPR due to the various culling protocols applied in Hungary.

PR is much more informative than SPC when it comes to the evaluation of reproduction. Good SPC does not necessarily mean good PR, because the latter is greatly influenced by SP, as well. The results of this study confirm that SPC should not be regarded as one of the most important parameters during a quick-check.

\section{VWP and CRI}

It was revealed in the present study, that VWP is generally not applied in the Hungarian dairies as strictly as in the US, since cows showing oestrus signs early in lactation are often inseminated. Huge differences (even 100 days!) may appear in the days to first insemination among the cows, however, the average may remain on a good level. The range of days to first inseminations has to be considered, too, when determining the real VWP. 
CR1 provides information about the quality of the uterine involution and the energetic status in the early lactation, therefore, shows the adequate time of first inseminations. Remarkable difference in CR1 was shown between the high- and low-PR groups in Table 2. (average: $28.8 \%$ vs. $19.5 \%$ ). Higher CR1 may have played a role in the better SP200 result of the high-PR group (101.8 vs. 116.5 days), furthermore, CR1 is essential for a good SPC, as well.

The length of the VWP should be tailored to the characteristics (human resource, technology, feeding, etc.) of the dairy farm. DS1I, CR1 and SP200 provide assistance in the setting up and controlling of VWP.

\section{The application of $\%$ PORP in Hungarian dairy farms}

The proportion of pregnant cows is an important issue, however, analyses should be carried out prudently, since a number of factors may influence the results, e.g. the date and frequency of pregnancy check, and the time of recording of the findings of the pregnancy check in the farm management software (either at the early pregnancy diagnosis or when the pregnancy is confirmed).

The difference between \%Preg and \%PORP and the influence of the pregnancy check on these parameters are shown in Table 6.

Table 6. The relationship of \%Preg and \%PORP and their changes after pregnancy diagnosis

\begin{tabular}{|l|c|c|c|c|c|c|}
\hline \multicolumn{1}{|c|}{ Time of data recording } & $\begin{array}{c}\text { Total } \\
\text { No. of } \\
\text { cows }\end{array}$ & $\begin{array}{c}\text { No. of } \\
\text { pregnant } \\
\text { cows }\end{array}$ & \%Preg & $\begin{array}{c}\text { Cull } \\
\text { cows }\end{array}$ & $\begin{array}{c}\text { Within } \\
\text { VWP }\end{array}$ & \%PORP \\
\hline Before pregnancy check & 589 & 251 & $42.6 \%$ & 12 & 32 & $46.1 \%$ \\
\hline $\begin{array}{l}\text { Before pregnancy check, } \\
\text { after culling }\end{array}$ & 589 & 251 & $42.6 \%$ & 14 & 32 & $46.2 \%$ \\
\hline After pregnancy check & 589 & 304 & $51.6 \%$ & 14 & 38 & $56.6 \%$ \\
\hline
\end{tabular}

Source: own calculation

The difference is remarkable between \%Preg (which compares the proportion of pregnant cows to the size of the whole herd) and \%PORP (which considers only the optimal reproductive population). The difference may be further enlarged by cullings and seasonal dump calvings. Both parameters improved significantly after pregnancy check, thus, the time of pregnancy diagnosis relative to the evaluation of these parameters should be clarified.

The advantage of \%PORP is the same as that of PR: both express the performance of the reproductive population. The disadvantage of \%PORP is that comparisons can only be made after pregnancy diagnosis. 
Fodor, I. - Kranjec, F. - Ózsvári, L.

\section{Conclusions}

The evaluation of reproductive performance has become very diverse among the dairy herds in Hungary due to the changes of the Holstein-Friesian cows, housing, feeding and imported techniques and evaluation systems from the US. Farmers should receive more up-to-date information about the achievable goals instead of using outdated reference numbers.

The present work revealed that these outdated reference numbers cannot be achieved even by the best herds. PR turned out to be useful among Hungarian circumstances, however, culling intensity should be taken into account when evaluating this index. Therefore, cPR was developed, which aims to overcome difficulties stemming from the Hungarian culling policy. The regular recording and analysis of some relevant parameters is adequate for the daily routine, but in-depth analysis is required when the reproductive performance is diminishing.

\section{References}

1. DCRC (2014): Dairy Cattle Reproduction Council's Platinum Winners, 64th Annual Round Table. Hoard's Dairyman, November 2014. 735-737.

2. Farin, P. W.; Slenning, B. D. (2001): Managing Reproductive Efficiency in Dairy Herds. In: Herd Health, ed. Radostits, O.M., Saunders, Philadelphia, pp. 255-289.

3. Fetrow, J.; Stewart, S.; Eicker, S.; Rapnicki, P. (2007): Reproductive Health Programs for Dairy Herds: Analysis of Records for Assessment of Reproductive Performance. In: Current Therapy in Large Animal Theriogenology, eds Youngquist, R.S. \& Threlfall, W.R., Saunders, Philadelphia, pp. 473-489.

4. Fodor, I. (2011): Economic losses due to main diseases in dairy herds. Students' Research Circle work, Szent István University Faculty of Veterinary Science, Budapest, p. 43.

5. Lucy, M. C. (2001): Reproductive loss in high-producing dairy cattle: where will it end? Journal of Dairy Science, 84. 1277-1293.

http://dx.doi.org/10.3168/jds.S0022-0302(01)70158-0

6. Nebel, F. L.; Mcgilliard, M. L. (1993): Interactions of high milk yield and reproductive performance in dairy cows. Journal of Dairy Science, 76. 3257-3268. doi:10.3168/jds.S0022-0302(93)77662-6

7. Nebel, R. L; Dransfield, M. G.; Jobst, S. M.; Bame, J. H. (2000): Automated electronic systems for the detection of oestrus and timing of AI in cattle. Animal Reproduction Science, 61. 713-723. doi:10.1016/S0378-4320(00)00090-7

8. Ózsvári, L. (2004): Economic analysis of decisions with respect to dairy cow health management (in Hungarian with English thesis). Doctoral (PhD) dissertation. SZIU-FVS, Gödöllő, p. 145.

9. Ózsvári, L. (2013): A szarvasmarha állomány-egészségügy gazdasági kérdései. In: Gyakori szarvasmarha-betegségek, ed. Winfried, H., Mezőgazda Kiadó - Nemzeti Agrárgazdasági Kamara, Budapest, pp. 211-236. 
10. Ózsvári, L.; Kerényi, J. (2004): Quantification of losses due to reproductive disorders on a large-scale Holstein-Friesian dairy farm (in Hungarian with English abstract). Magy. Áo. Lapja, 126. 523-531.

11. Pécsi, T. (ed.) (2007): Házi emlösállatok mesterséges termékenyítése, Budapest, Mezőgazda Kiadó. p. 185.

12. Radostits, O. M.; Leslie, K. E.; Fetrow, J. (1994): Herd Health. Food Animal Production Medicine. 2nd edition. Saunders Company, London: W.B. 603.

13. Stevenson, J. S. (2011): Alternative programs to presynchronize estrous cycles in dairy cattle before a timed artificial insemination program. Journal of Dairy Science, 94. 205-217. http://dx.doi.org/10.3168/jds.2010-3375

14. Szenci, O. (1999): Az ellés utáni időszak szaporodásbiológiai gondozása tejhasznú tehenészetekben. Magy. Áo. Lapja 121. 78-81 . 